\title{
Posture and Social Problem Solving, Self-Esteem, and Optimism
}

\author{
Sarah K. Nielsen ${ }^{1}$ \\ ${ }^{1}$ High Point University, High Point, NC, USA \\ Correspondence: Sarah K. Nielsen, Department of Human Relations, High Point University, One University \\ Parkway, High Point, NC, 27268, USA. Tel: 1-336-841-9570. E-mail: snielsen@highpoint.edu
}

Received: October 6, 2017

Accepted: October 24, 2017

Online Published: November 7, 2017

doi:10.5539/ijps.v9n4p44

URL: http://doi.org/10.5539/ijps.v9n4p44

\begin{abstract}
When feeling powerful humans and other animals display expansive postures, but can posing in expansive and powerful postures also generate empowerment? Researchers have studied the "power posing effect" the concept that powerful expansive postures generate empowerment, and found conflicting evidence. Some evidence of power posing's impact shows increased hormones and a variety of behaviors indicating greater confidence. Yet still others have found no effect on hormones or behaviors, and suggest the impact of power posing is overstated. The goal of this project was to replicate and extend previous knowledge and contribute to the debate as to the efficacy of power posing, specifically examining the impact on participants' self-reported social problem-solving efficacy, self-esteem, and optimism. 119 participants were randomly assigned to one of three conditions: high power pose, low power pose, or a control group with a puzzle solving task, and asked to complete self-report measures of optimism, self-esteem, and problem-solving self-efficacy. Current findings suggest expansive posture demonstrates no measurable impact on psychological attitudes, and contributes to recent literature contradicting the power posing effect. Research and practical implications are discussed.
\end{abstract}

Keywords: posture, power pose, problem solving, self-esteem, optimism, embodied cognition

\section{Introduction}

The study of physical postures has enjoyed a long history. In one of the first studies of postural display, Riskind and Gotay (1982) found motivational and emotional impact on both the self and others across a series of four studies. Participants seated in slumped positions more readily developed helplessness and were more likely to be perceived as depressed by observers than participants seated in an upright position. The link between posture and assumed dominance was solidified in 2005 when researchers established specific behaviors associated with dominance and power (Carney, Hall, \& LeBeau, 2009; Hall, LeBeau, \& Coats, 2005). Nonverbal behaviors identified with actual associations to power and dominance included more facial expressiveness, more bodily openness, smaller interpersonal distances, relaxed sounding voices, and greater verbal expression.

In more recent time, researchers began to turn the investigation of posture inward to the actor and the socioemotional and cognitive impact. Harmon-Jones and Peterson (2009) explored how bodily posture impacts emotional judgment by tracking neural cortical activity, concluding that sitting upright primed subjects for motivation and activated the left prefrontal cortex as compared to subjects in reclined positions. Schubert and Koole (2009) found participants reported increased feelings of empowerment after holding a fist, considered a dominant posture.

Social science research has found that the act of smiling both produces and reflects positive mood (McIntosh, 1996; Strack, Martin, \& Stepper, 1988), known as the "facial feedback hypothesis". Similarly, a growing number of studies have investigated the relationship between expansive nonverbal behaviors and indications of power or powerlessness, suggesting that expansive physical expression both reflects and also produces power. Research has found that holding dominant or expansive postures increases subjects' feelings of power, confidence, pain tolerance, self-esteem, and lowers fear (Huang, Galinsky, Gruenfeld, \& Guillory, 2011; Bohns \& Wiltermuth, 2012; Nair, Sagar, Sollers, Consedine, \& Broadbent, 2014). In fact, posing powerfully is reported to have a greater impact on subjects' action orientation and thought abstraction than by actually occupying a powerful role (Huang, Galinsky, Gruenfeld, \& Guillory, 2011). Unfortunately, expansive posturing increases the more negative side of power as well, such as subjects' dishonesty, risk tolerance, cheating, and traffic violations (Carney, Cuddy, \& Yap, 2010; Yap, Wazlawek, Lucas, Cuddy, \& Carney, 2013). 
In addition to the many behavioral and attitudinal effects of expansive posturing, there is evidence linking it to hormonal and neuroendocrine changes. In particular, dominant poses increase salivary and blood serum levels of testosterone, which is a hormone linked to dominance and status-seeking, while lowering levels of cortisol, a hormone linked to stress and low social status (Carney, Cuddy, \& Yap, 2010). Together this hormonal combination suggests power posing leaves a subject feeling dominant and powerful, while also less stressed. A potent hormonal interaction, greater testosterone and lower cortisol has been linked to hierarchical position and status for business executives, suggesting greater leadership potential (Sherman, Lerner, Josephs, Renshon, \& Gross, 2016).

An interesting outcome of greater empowerment is the potential impact it may have on a subject in evaluative social situations such as job interviews, work evaluations, etc. Research has found executive functioning increases with expansive posturing such as greater cognitive processing and goal-oriented behaviors (Smith, Dijksterhuis, \& Wigboldus, 2008; Smith, Jostmann, Galinsky, \& van Dijk, 2008). The cognitive processing gains of empowerment combined with the psychological and hormonal changes including increased testosterone, lowered cortisol, and greater confidence and self-esteem, for instance, have potential to greatly improve performance. Participants who were primed to think of powerful moments in their lives before applying for admission to business schools were judged as more persuasive and chosen for admission for than those who were not primed (Lammers, Dubois, Rucker, \& Galinsky, 2013). Indeed, research has found that subjects who engaged in power posing prior to job interviews were more frequently chosen for hire (Carney et al., 2010; Cuddy, Wilmuth, Yap, \& Carney, 2015).

\subsection{Metacognition}

Researchers have begun to unpack the mechanisms through which confidence and positive attitudes are facilitated with expansive posture. According to the self-validation perspective, metacognition has a strong impact on the persuasiveness of the thoughts in our attention (Petty, Briñol, \& Tormala, 2002). Interestingly, researchers found that posture increased thought confidence such that it either magnified or attenuated the effect of any thoughts participants were considering. For example, Bristol and Petty (2003) found that when participants generated positive thoughts toward a proposal while in expansive posture their positive thoughts were more confident and more positive than those generated while in constricted posture. Likewise, negative thoughts generated while in expansive posture were more negative than those generated in constricted posture due to the increased confidence in their thoughts.

This self-validation effect is not limited to attitudes toward others and, in fact, has been found to influence self-evaluations. Expansive body posture magnified the direction of thoughts (whether positive or negative) on self-related attitudes, while constricted posture attenuated the effect (Briñol, Petty, \& Wagner, 2009) by impacting the confidence with which people held their thoughts. This self-validation impacted the extent to which participants relied on their thoughts when forming self-attitudes and judging their promise as a potential job candidate. When in a confident pose, participants relied on their thoughts when forming self-attitudes, but not when they held doubtful postures.

Body posture has been directly linked to a variety of important cognitive processes, specifically the metacognitive process of thought confidence (Briñol et al., 2009), confirmatory processing (Fischer, J., Fischer, P., Englich, Aydin, \& Frey, 2011), and action orientation (Huang et al., 2011). It has also been associated with several behavioral indicators such as puzzle solving persistence (Riskind \& Gotay, 1982), job interview performance and nonverbal presence (Cuddy, Wilmuth, Yap, \& Carney, 2015). Research has yet to examine, however, a specific link between expansive posture and problem-solving through thought confidence. The present study seeks to examine potential gains on problem solving skill as well as problem solving efficacy, a measure of problem solving confidence, from thought confidence through expansive posture.

\section{H1. Expansive posturing will predict higher ratings of a) social problem-solving efficacy and b) skill.}

\subsection{Emotions \& Attitudes}

The study of muscular changes and emotion is as old as the study of psychology itself and began with William James (1890). Since that time most research has focused on the facial feedback hypothesis (Tourangeau \& Ellsworth, 1979) until recently with a greater focus on embodied cognition (Niedenthal, 2007). Posture itself has been linked to negative emotion and specifically identified as a feature of depression (Michalak et al., 2009). Bem (1972) suggests self-observation and attribution may be to blame such that if we are hunched over we infer that we are sad, etc. More recent examinations of this link have found greater positivity, more arousal, better mood, and less fear after holding expansive posture (Nair, Sagar, Sollers, Consedine, \& Broadbent, 2015). 
The present study seeks to further examine the link between posture and positive emotions, and hypothesizes the following:

\section{H2. Expansive posturing will predict higher ratings of a) optimism and b) self-esteem.}

\subsection{Contribution to Literature}

While previous research provides support for the impact of embodied cognition on a myriad of biopsychosocial outcomes, such as hormonal changes (Carney et al., 2010), cognitive processing gains (Smith et al., 2008), and selection outcomes (Carney et al., 2010; Lammers et al., 2013), recent evidence suggests the claims of power posing benefits may be overstated. In their recent conceptual replication of the well known Carney, Cuddy, and Yap (2010) study, Ranehill et al. (2015) found that while expansive posture impacted participants' self-reported feelings of power it did not impact participants' behavior or hormonal levels. Their findings suggest that the impact of power posing may be quite limited, or at the least, subject to moderation by very specific conditions such as gender, awareness of the hypothesis of the experiment or the "cover story" variable, timing of the posture, and the experimenters' blindness to the experiment. In their rebuttal, Carney, Cuddy, and Yap (2015) discussed evidence of expansive posture and power posing research across 33 studies and suggested Ranehill et al.'s results are due to methodological differences. However, that summary did not include quantitative analyses across findings. Simmons and Simonsohn (2017) examined the research previously summarized in Carney et al. (2015) using $p$-curve analysis and found no evidence of an effect after accounting for selective reporting. Research on the "power posing effect" and the impact of expansive posture on both attitudes and behavior is clearly mixed. The current study proposes to investigate possible links between expansive posturing, cognitive processing, and attitudes, and will contribute to a resolution of the debate in the literature regarding future directions for embodied cognition research.

\section{Method}

\subsection{Participants}

A total of 123 undergraduate students from a private American university in the South participated in this study. $92 \%$ of participants identified as White (5\% Black, 3\% Hispanic) and $85 \%$ female, and were on average 20 years old.

\subsection{Procedures}

This study utilized an experimental design. Participants were voluntarily recruited and told the purpose of the study was to "investigate the relationship between nonverbal behavior and attitudes". After participants provided their informed consent, they were randomly assigned to one of three groups, either 1) the expansive "high power" pose, 2) the constricted "low power" pose, or 3) a control group with a puzzle activity. They were asked to hold the pose or work the puzzle for two minutes while the experimenter left the room. After two minutes, the participants were asked to provide their self-evaluations using an online survey.

Previous research has established some postures and poses are perceived as more powerful than others (Carney, Cuddy, \& Yap, 2010). The high power poses involve expansive bodily position with open limbs, while low power poses involve contractive positions with closed limbs. Project participants were instructed and lightly directed by hand, when necessary, to hold either a low or high power pose. Please refer to Figure 1 for detailed poses used in the experimental conditions. 


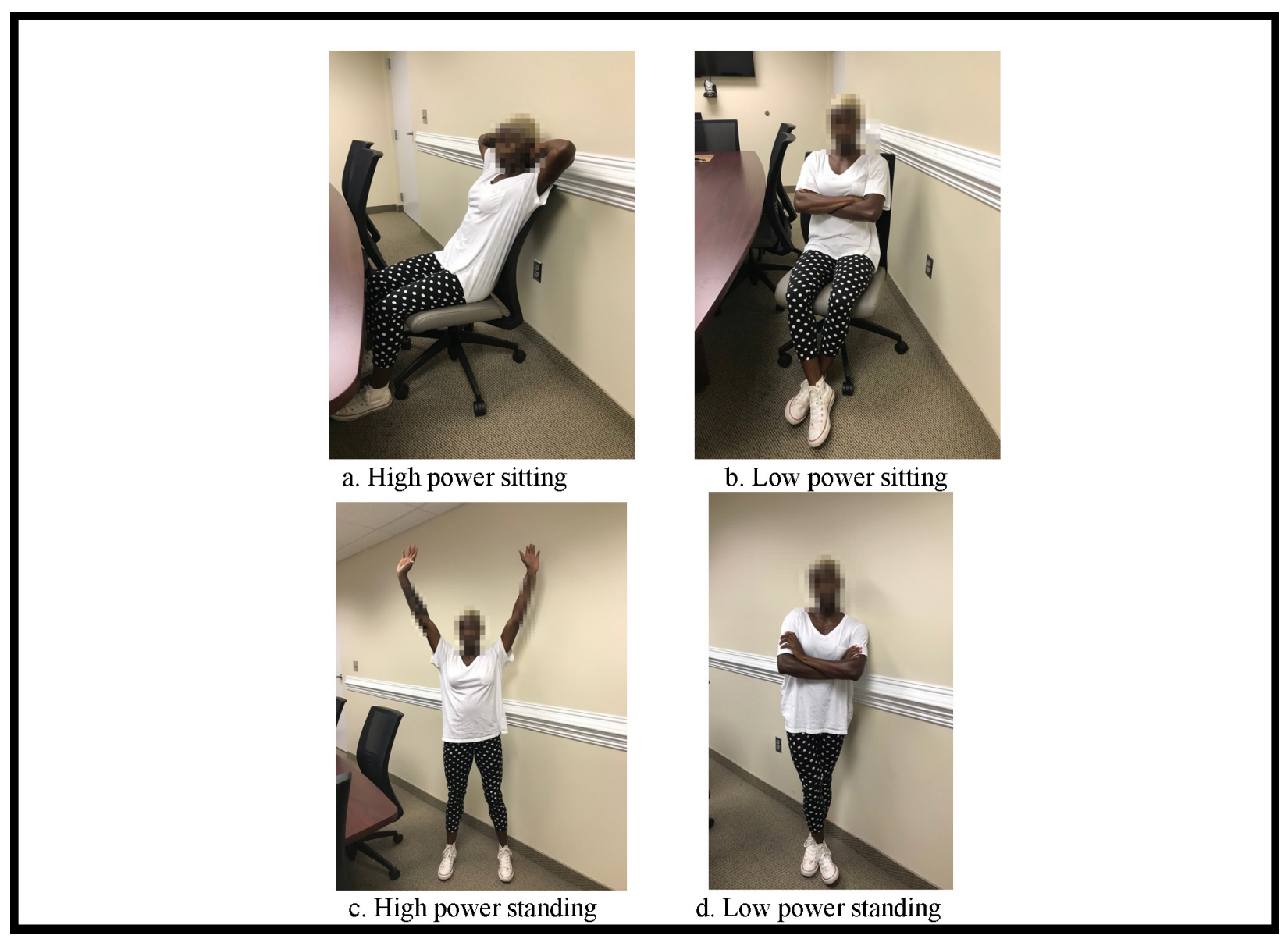

Figure 1. Poses for experimental conditions

\subsection{Measures}

After participants held the high/low power pose or worked the puzzle for two minutes, they were asked to complete a series of online surveys measuring optimism, self-esteem, and problem-solving confidence.

Optimism was measured using the 10-item Revised Life Orientation Test (RLOT; Scheier, Carver, \& Bridges, 1994; $\propto=.67$ ). Respondents are asked to indicate the extent of their agreement with each of the items using a five-point scale from 1 (strongly disagree) to 5 (strongly agree). Four of the items are filler items and are not included in scoring. Of the remaining six items, three are worded positively and three are negatively worded and are reverse coded before scoring such that responses are summed to create an overall optimism score. The range of possible scores include 5-30, and the mean score of participants in this study was 22 with a $S D$ of 2.9. Sample items from this scale include, "In uncertain times, I usually expect the best" and "If something can go wrong for me, it will (reverse scored)".

Self-esteem was measured using Rosenberg's (1965) Self-esteem Scale $(\propto=.83)$. The scale has 10 items, with five each worded positively or negatively. Negatively worded items are reverse coded before scoring such that responses are summed to create an overall self-esteem score. The range of possible scores include 10-50, and the mean score of participants in this study was 38 , with a $S D$ of 4.5 . Sample items from this scale include, "On the whole, I am satisfied with myself" and "At times, I think I am no good at all (reverse scored)".

Problem-solving confidence was measured using the Problem Solving Inventory (Maydeu-Olivares \& D'Zurilla, 1997). This measure includes two subscales: 1 ) the Problem Solving Self-Efficacy measure (PSSE; $\propto=.73$ ), which specifically measures one's efficacy or confidence regarding one's ability to solve problems, and 2) the Problem Solving Skill measure (PSS; $\propto=.65$ ), which assesses one's constructive and dysfunctional problem-solving dimensions. The PSSE is a seven-item scale with five items worded positively and two items worded negatively. The PSS is a nine-item scale with six items worded positively and three items worded negatively. The negatively worded items were recoded such that all scale responses are summed to create an 
overall PSSE and PSS score. The range for the PSSE was 7-35 with a mean of 26 and a $S D$ of 2.8, while the range for PSS was 9-45 with a mean of 33 and $S D$ of 3.6. A sample item from the PSSE includes "Many of the problems I face are too complex for me to solve (reverse scored)". A sample item from the PSS includes "When I have a problem, I think of as many possible ways to handle it as I can until I can't come up with any more ideas".

\section{Results}

All variable descriptive statistics and correlation coefficients can be found in Table 1.

Table 1. Descriptive statistics and intercorrelations

\begin{tabular}{|c|c|c|c|c|c|c|c|c|c|}
\hline Variable & $M$ & $S D$ & 1 & 2 & 3 & 4 & 5 & 6 & 7 \\
\hline 1. Age & 19.9 & 1.1 & - & & & & & & \\
\hline 2. Gender & 1.8 & .36 & -.15 & - & & & & & \\
\hline 3. Optimism & 22.1 & 2.9 & .02 & $.18^{*}$ & (.64) & & & & \\
\hline 4. Self-esteem & 38.7 & 4.6 & .10 & .02 & $.53 * *$ & $(.83)$ & & & \\
\hline 5. PS Self-efficacy & 26.4 & 2.8 & .18 & $-.21 *$ & $.28 * *$ & $.47 * *$ & $(.73)$ & & \\
\hline 6. PS Skill & 33.0 & 3.6 & -.03 & -.04 & .17 & $.27 * *$ & .16 & $(.65)$ & \\
\hline
\end{tabular}

Note. $N=123$. The alpha internal-consistency reliabilities appear in parentheses along the main diagonal. ${ }^{*} p<.05 . *^{*} p<.01$.

H1. Expansive posturing will predict higher ratings of a) social problem-solving efficacy and b) skill.

H2. Expansive posturing will predict higher ratings of a) optimism and b) self-esteem.

The hypotheses were tested using one-way analysis of variance. Group means for optimism, self-esteem, problem solving self-efficacy, and problem solving skill were compared by pose (either high power, low power, or control). Analysis of variance showed no significant effect of pose on optimism, $F(2,120)=.706, p=.495$. Pose also showed no effect on self-esteem, $F(2,120)=.446, p=.642$. No main effect was found for pose on problem solving self-efficacy, $F(2,120)=1.14, p=.323$, nor on problem solving skill, $F(2,120)=.034, p=.967$. All statistics for the ANOVA can be found in Table 2.

Table 2. One-way ANOVA results

\begin{tabular}{|c|c|c|c|c|c|c|}
\hline & & $\begin{array}{l}\text { Sum of } \\
\text { Squares }\end{array}$ & $\mathrm{df}$ & Mean Square & $F$ & Sig. \\
\hline \multirow[t]{3}{*}{ Optimism } & Between Groups & .25 & 2 & .13 & .71 & .50 \\
\hline & Within Groups & 21.51 & 120 & .18 & & \\
\hline & Total & 21.76 & 122 & & & \\
\hline \multirow[t]{3}{*}{ Self Esteem } & Between Groups & .19 & 2 & .09 & .45 & .64 \\
\hline & Within Groups & 25.13 & 120 & .21 & & \\
\hline & Total & 25.32 & 122 & & & \\
\hline \multirow{3}{*}{$\begin{array}{l}\text { Problem Solving Self } \\
\text { Efficacy }\end{array}$} & Between Groups & .35 & 2 & .18 & 1.14 & .32 \\
\hline & Within Groups & 18.64 & 120 & .16 & & \\
\hline & Total & 18.99 & 122 & & & \\
\hline \multirow[t]{3}{*}{ Problem Solving Skills } & Between Groups & .01 & 2 & .01 & .03 & .97 \\
\hline & Within Groups & 20.01 & 120 & .17 & & \\
\hline & Total & 20.03 & 122 & & & \\
\hline
\end{tabular}




\section{Discussion}

The current project sought to expand knowledge of embodied cognition and provide resolution to the debate regarding the utility and validity of the "power posing effect". Specifically, we sought to investigate how expansive posture impacts one's confidence for problem-solving as well as the psychological attitudes of self-esteem and optimism. While previous research provides evidence for a positive relationship between posture and self-esteem and improved mood (Nair, Sagar, Sollers, Consedine, \& Broadbent, 2015) as well as evidence linking posture with overall thought confidence/metacognition (Briñol, Petty, \& Wagner, 2009), recent research suggests the impact of power posing or attitudes and behavior may be quite limited (Ranehill et al., 2015; Simmons \& Simonsohn, 2017). The current findings, or lack thereof, between power posing, psychological attitudes and problem-solving self-efficacy provide additional evidence in the debate against the validity of power posing and its practical utility. A variety of points may provide context for these results.

Several study characteristics may provide alternative explanations for current results. For instance, the popularity and widespread coverage of nonverbal expansiveness in both the media as well as in university classrooms and textbooks may result in a bit of overexposure to the research, belying the purpose of the current experiment. This overexposure coupled with the lack of a "cover story" for participants may have an impact on subjects' posture and self-evaluations. The current study did not use a cover story and instead participants were explicitly told that the purpose of the study was to "investigate the relationship between nonverbal behavior and attitudes". Previous research indicates there may be a benefit from carefully framing the task for participants so that it does not moderate results (Carney, Cuddy, \& Yap, 2015).

The current study did not ask subjects to engage in a filler task during the pose, which may have impacted the findings. Previous research suggests that instead of a direct or immediate effect on psychological states, bodily states instead provide context that the mind interprets as possible action (Cesario \& McDonald, 2013). For instance, expansive poses impacted participants' empowerment only when they were experienced in interpersonally relevant contexts, suggesting that embodiment is largely impacted by the context in which the pose is experienced. In this study, posing with no filler task may have done little to provide interpersonal context, which could limit the impact of posing on psychological states. However, some studies have found effects using tasks without social components, such as Fischer et al. (2011), who found expansive posture resulted in increased feelings of power, and Yap et al. (2013) who found that expansive posture increased risk of negative behaviors like cheating.

Outside of individual study or sample effects, the lack of findings in the current study suggests there is much about embodied cognition for researchers to discover. Initial power analysis based on the effect sizes found in similar studies in the field (power=.8, $\propto=.05$; Carney, Cuddy, \& Yap, 2010; Ranehill et al., 2015), revealed a sample size of 103 participants would be suitable and the current sample was 123 participants. While this study had ample power to detect an effect, no effect was in fact present. A few possible explanations suggest that the present study may be missing a specific condition to induce the embodied cognition that has accompanied power posing in previous research. However, a more plausible explanation, and one that has been echoed by other researchers, is that we clearly have yet much to learn regarding specific conditions impacting embodied cognition (Ranehill et al., 2015).

The current study contributes to the power posing literature by confirming new directions in the field of study. Increasing research in recent years suggests that while widespread popularity continues in the media and pop culture the impact of power posing on psychological attitudes and behavior is in fact very limited. Indeed, continued reexamination of the Carney, Cuddy, and Yap (2010) study that sparked initial interest in power posing has resulted in Carney suggesting a moratorium on continued investigation (Carney, n.d.). The present research study confirms this direction and provides evidence that expansive posturing does not have measurable effect on behavior. Taken in consideration with the current findings, future implications should include the possibility that the conditions under which expansive and constrictive posture impacts psychological states is so limited as to be rendered impractical. This stands in direct contradiction to the widespread media message of power posing as a "life hack" (Clear, 2013) or "life-changing" (Blodget, 2013).

This is not to say that embodied emotion and cognition as broader constructs are impractical. Quite the contrary, there is ample evidence of the existence of the power of embodiment to influence psychological states (Duckworth, Bargh, Garcia, \& Chaiken, 2002; Hall et al., 2005; Niedenthal, 2007; Stepper \& Strack, 1993; Tom, Pettersen, Lau, Burton, \& Cook, 1991). Given the debate about the robustness of the power posing effect, researchers clearly have a great deal yet to discover about embodied cognition and embodied empowerment. However, given the lack of replicability across a variety of contexts, the growing evidence of power posing's 
limited effects on psychological states, behavior, and hormones, it is ill advised to continue researching the "power pose" specifically.

\section{References}

Bem, D. J. (1972). Self-perception theory. In L. Berkowitz (Ed.), Advances in experimental social psychology (Vol. 6, pp. 2-62). New York, NY: Academic Press. https://doi.org/10.1016/S0065-2601(08)60024-6

Blodget, H. (2013, May 3). This simple "power pose" can change your life and career. Business Insider. Retrieved June 1, 2017, from http://www.businessinsider.com/power-pose-2013-5?op=1/\#amy-cuddy-is-a-social-psychologist-and-profes sor-at-harvard-business-school-1

Bohns, V., \& Wiltermuth, S. (2012). It hurts when I do this (or you do that): Posture and pain tolerance. Journal of Experimental Social Psychology, 48, 341-345. https://doi.org/10.1016/j.jesp.2011.05.022

Briñol, P., \& Petty, R. E. (2003). Overt head movements and persuasion: A self-validation analysis. Journal of Personality and Social Psychology, 84, 1123-1139. https://doi.org/10.1037/0022-3514.84.6.1123

Briñol, P., Petty, R. E., \& Wagner, B. (2009). Body posture effects on self-evaluation: A self-validation approach. European Journal of Social Psychology, 39, 1053-1064. https://doi.org/10.1002/ejsp.607

Carney, D. (n.d.). My position on "power poses" [Web log post]. Retrieved June 1, 2017, from http://faculty.haas.berkeley.edu/dana_carney/pdf_My\%20position\%20on\%20power\%20poses.pdf

Carney, D. R., Cuddy, A. J., \& Yap, A. J. (2010). Power posing: Brief nonverbal displays affect neuroendocrine levels and risk tolerance. Psychological Science, 21, 1363-1368. https://doi.org/10.1177/0956797610383437

Carney, D. R., Hall, J., \& Smith LeBeau, L. (2005). Beliefs about the nonverbal expression of social power. Journal of Nonverbal Behavior, 29, 105-123. https://doi.org/10.1007/s10919-005-2743-z

Clear, J. (2013, July 25). How to be confident and reduce stress in 2 minutes per day [Web log post]. Retrieved June 1, 2017, from http://jamesclear.com/body-language-how-to-be-confident

Cuddy, A. J. C., Wilmuth, C. A., Yap, A., \& Carney, D. R. (2015). Preparatory power posing affects nonverbal presence and job interview performance. Journal of Applied Psychology, 100(4), 1286-1295. https://doi.org/10.1037/a0038543

Duckworth, K. L., Bargh, J. A., Garcia, M., \& Chaiken, S. (2002). The automatic evaluation of novel stimuli. Psychological Science, 13(6), 513-519. https://doi.org/10.1111/1467-9280.00490

Fischer, J., Fischer, P., Englich, B., Aydin, N., \& Frey, D. (2011). Empower my decision: The effects of power gestures on confirmatory information processing. Journal of Experimental Social Psychology, 47, 1146-1154. https://doi.org/10.1016/j.jesp.2011.06.008

Hall, J. A., Coats, E. J., \& LeBeau, L. S. (2005). Nonverbal behavior and the vertical dimension of social relations: A meta-analysis. Psychological Bulletin, 131, 898-924. https://doi.org/10.1037/0033-2909.131.6.898

Harmon-Jones, E., \& Peterson, C. K. (2009). Supine body position reduces neural response to anger evocation. Psychological Science, 20(10), 1209-1211. https://doi.org/10.1111/j.1467-9280.2009.02416.x

Huang, J., Galinsky, A. D., Gruenfeld, D. H., \& Guillory, L. E. (2011). Powerful postures versus powerful roles: Which is the proximate correlate of thought and behavior? Psychological Science, 22, 95-102. https://doi.org/10.1177/0956797610391912

James, W. (1890). The principles of psychology. New York, NY: Holt. https://doi.org/10.1037/11059-000

Lammers, J., Dubois, D., Rucker, D. D., \& Galinsky, A. D. (2013). Power gets the job: Priming power improves interview outcomes. Journal of Experimental Social Psychology, 49, 776-779. https://doi.org/10.1016/j.jesp.2013.02.008

Maydeu-Olivares, A., \& D'Zurilla, T. J. (1997). The factor structure of the Problem Solving Inventory. European Journal of Psychological Assessment, 13(3), 206-215. https://doi.org/10.1027/1015-5759.13.3.206

McIntosh, D. N. (1996). Facial feedback hypotheses: Evidence, implications, and directions. Motivation and Emotion, 20, 121-147. https://doi.org/10.1007/BF02253868 
Michalak, J., Troje, N. F., Fischer, J., Vollmar, P., Heidenreich, T., \& Schulte, D. (2009). Embodiment of sadness and depression-Gait patterns associated with dysphoric mood. Psychosomatic Medicine, 71, 580-587. https://doi.org/10.1097/PSY.0b013e3181a2515c

Nair, S., Sagar, M., Sollers, J., Consedine, N., \& Broadbent, E. (2015). Do slumped and upright postures affect stress responses? A randomized trial. Health Psychology, 34(6), 632-641. https://doi.org/10.1037/hea0000146

Niedenthal, P. M. (2007). Embodying emotion. Science, 316(5827), 1002-1005. https://doi.org/10.1126/science.1136930

Petty, R. E., Briñol, P., \& Tormala, Z. L. (2002). Thought confidence as a determinant of persuasion: The self-validation hypothesis. Journal of Personality and Social Psychology, 82(5), 722-741. https://doi.org/10.1037/0022-3514.82.5.722

Ranehill, E., Dreber, A., Johannesson, M., Leiberg, S., Sul, S., \& Weber, R. (2015). Assessing the robustness of power posing: No effect on hormones and risk tolerance in a large sample of men and women. Psychological Science, 26(5), 653-656. https://doi.org/10.1177/0956797614553946

Riskind, J. H., \& Gotay, C. (1982). Physical posture: Could it have regulatory or feedback effects on motivation and emotion? Motivation and Emotion, 6(3), 273-298. https://doi.org/10.1007/BF00992249

Rosenberg, M. (1965). Society and the adolescent self-image. Princeton, NJ: Princeton University Press. https://doi.org/10.1515/9781400876136

Scheier, M. F., Carver, C. S., \& Bridges, M. W. (1994). Distinguishing optimism from neuroticism (and trait anxiety, self-mastery, and self-esteem): A reevaluation of the Life Orientation Test. Journal of Personality and Social Psychology, 67(6), 1063-1078. https://doi.org/10.1037/0022-3514.67.6.1063

Schubert, T. W., \& Koole, S. L. (2009). The embodied self: Making a fist enhances men's power-related self-conceptions. Journal of Experimental Social Psychology, 45, 828-834. https://doi.org/10.1016/j.jesp.2009.02.003

Sherman, G. D., Lerner, J. S., Josephs, R. A., Renshon, J., \& Gross, J. J. (2016). The interaction of testosterone and cortisol is associated with attained status in male executives. Journal of Personality and Social Psychology, 110(6), 921-929. https://doi.org/10.1037/pspp0000063

Simmons, J. P., \& Simonsohn, U. (2017). Power posing: P-curving the evidence. Psychological Science, 28(5), 687-693. https://doi.org/10.1177/0956797616658563

Smith, P. K., Dijksterhui, A., \& Wigboldus, D. H. J. (2008). Powerful people make good decisions even when $\begin{array}{lllll}\text { they consciously think. Psychological } & \text { Science, } & 19, & 1258-1259 .\end{array}$ https://doi.org/10.1111/j.1467-9280.2008.02207.x

Smith, P. K., Jostmann, N. B., Galinsky, A. D., \& van Dijk, W. W. (2008). Psychological Science, 19(5), 441-447. https://doi.org/10.1111/j.1467-9280.2008.02107.x

Stepper, S., \& Strack, F. (n.d.). Proprioceptive determinants of emotional and nonemotional feelings. Journal of Personality and Social Psychology, 64(2), 211-220.

Strack, F., Martin, L. L., \& Stepper, S. (1988). Inhibiting and facilitating conditions of the human smile: A nonobtrusive test of the facial feedback hypothesis. Journal of Personality and Social Psychology, 54, 768-777. https://doi.org/10.1037/0022-3514.54.5.768

Tom, G., Pettersen, P., Lau, T., Burton, T., \& Cook, J. (1991). The role of overt head movement in the formation of affect. Basic and Applied Social Psychology, 12(3), 281-289. https://doi.org/10.1207/s15324834basp1203_3

Tourangeau, R., \& Ellsworth, P. C. (1979). The role of facial response in the experience of emotion. Journal of Personality and Social Psychology, 37, 1519-1531. https://doi.org/10.1037/0022-3514.37.9.1519

Yap, A. J., Wazlawek, A. S., Lucas, B. J., Cuddy, A. J. C., \& Carney, D. R. (2013). The ergonomics of dishonesty: The effect of incidental posture on stealing, cheating, and traffic violations. Psychological Science, 24, 2281-2289. https://doi.org/10.1177/0956797613492425 


\section{Copyrights}

Copyright for this article is retained by the author(s), with first publication rights granted to the journal.

This is an open-access article distributed under the terms and conditions of the Creative Commons Attribution license (http://creativecommons.org/licenses/by/4.0/). 